\title{
A negação da nomenclatura e o isolamento do nome próprio
}

\author{
Stefania Montes Henriques ${ }^{1}$
}

\section{Resumo}

Neste artigo, investigamos as considerações de Ferdinand de Saussure sobre a categoria linguistica dos nomes próprios, especificamente na obra responsável pela fundação da Linguística Moderna: o Curso de Linguística Geral. Com o intuito de apreender de que maneira o nome próprio é considerado nessa obra, priorizamos dois pontos principais: a negação da nomenclatura e a única menção dessa categoria feita no CLG. Partimos do pressuposto de que, apesar de não ser evidente, tanto a negação da nomenclatura quanto os nomes próprios relacionam-se com aspectos importantes da teoria saussuriana, tais como: arbitrariedade do signo, valor e parole.

Palavras-chave: Nomes próprios. Ferdinand de Saussure. CLG. Arbitrariedade

\footnotetext{
1 Graduada em Letras Português/Francês e respectivas literaturas. Mestre em Estudos Linguísticos pela Universidade Federal de Uberlândia. Doutoranda em Linguística na Universidade Estadual de Campinas e Professora Substituta na Universidade Federal de Uberlândia. Participa do Grupo de Pesquisa Ferdinand de Saussure (GPFdS/UFU/CNPq) e do Grupo de Pesquisa em Aquisição da Linguagem (GPAL/Unicamp/CNPq).
} 


\section{Introdução}

A questão que norteará este artigo diz respeito à maneira com que as considerações saussurianas podem se relacionar com o conhecimento produzido sobre os nomes próprios no século XIX. Será que o linguista, apesar de negar veementemente a concepção de língua como nomenclatura, teria tomado uma posição acerca do funcionamento dos nomes próprios, tema bastante abordado no século $\mathrm{XIX}^{2}$ ? Acreditamos que a resposta seja afirmativa, ainda que muitos estudiosos tenham considerado que Saussure não teria nem sequer se dedicado ao estudo dessa categoria linguística. Dentre eles, podemos citar dois: Gary-Prieur (1991) e Seiler (2006). Gary-Prieur (1991) afirma que Saussure pode ser considerado como um exemplo da perspectiva de "marginalização do nome próprio". De acordo com ela, "uma reflexão sobre o signo linguístico deveria encontrar o nome próprio. Ora, o Curso de Linguística Geral é estranhamente mudo sobre esse ponto" (GARYPRIEUR, 1991, p. 12, tradução nossa) $)^{3}$ Seiler (2006), por sua vez, afirma que "Saussure estava prestes a perceber que os nomes próprios (no sentido amplo do termo) se encaixavam mal à sua teoria da natureza do signo linguístico" (SEILER, 2006, p. 99, tradução nossa) $)^{4}$.

Discordamos tanto de Gary-Prieur (1991) quanto de Seiler (2006). E isso porque partimos da hipótese de que os nomes próprios relacionam-se fundamentalmente com o princípio da arbitrariedade e com a distinção entre língua e fala. Apesar de essa relação não ser explicitada de maneira evidente, há indícios de que ela ocorra e, nesse sentido, não haveria marginalização do nome próprio, mas sim um movimento complexo de delimitação dessa categoria. Não obstante, ao relacionarmos o conceito de fala aos nomes próprios, partimos do pressuposto de que a tese das "exclusões saussurianas" não se sustenta e isso porque esse conceito está presente durante todo o CLG e é delimitado em sua relação com a língua (COELHO; HENRIQUES, 2014).

Com o intuito de evidenciar essa complexidade e a relação entre nomes próprios/arbitrariedade/fala, deter-nos-emos no CLG e nas edições críticas de Engler (1962) e de De Mauro (1972). Como veremos no decorrer deste artigo, o nome próprio apresenta-se de duas maneiras distintas nessa obra: i) de maneira negativa, como negação

\footnotetext{
2 Para maiores esclarecimentos sobre essa questão, conferir Henriques (2014).

3 "Une réflexion sur le signe linguistique devrait rencontrer le Nom Propre. Or le Cours de Linguistique Générale est étrangement muet sur ce point".

4 "Saussure était sur le point de se rendre compte que les noms propres (au sens large du terme) s'accordaient mal à sa théorie de la nature su signe linguistique".
} 
das concepções que consideravam a língua enquanto nomenclatura e ii) de maneira positiva, mencionada apenas uma vez na parte dedicada à Linguística Diacrônica. Considerando essas duas formas de ocorrência, tentaremos evidenciar a relação estabelecida entre os nomes próprios e o princípio da arbitrariedade do signo, a teoria do valor e a fala.

\section{A primeira crítica: a nomenclatura e o sistema linguístico}

As críticas à nomenclatura presentes no CLG não parecem possuir, em um primeiro momento, uma importância teórica. São poucas as suas ocorrências, sendo que em apenas três passagens Saussure cita a concepção que considera a língua como nomenclatura. De acordo com De Mauro (1972),

Essa crítica permaneceu entre as sombras para os editores do Curso, como também permaneceu para uma boa parte da linguística contemporânea, que não lhe compreendeu o alcance e continua mantendo a concepção de nomenclatura cuja origem remonta a Aristóteles (DE MAURO, 1972, p. 427, tradução nossa)5.

Como exemplo de linguistas contemporâneos que, apesar das críticas saussurianas, ainda optaram por considerar a linguagem como uma nomenclatura, De Mauro (1972) cita S. Ulmann e L. Antall. O que é conveniente ressaltar nesse ponto é que, tanto os editores quanto os linguistas que conheceram a teoria saussuriana não parecem ter percebido que essas críticas se relacionam intrinsecamente com aspectos importantes da teoria de Saussure, especificamente: o arbitrário, a natureza do signo linguístico e a ordem própria da língua.

Uma das razões para afirmarmos que essas críticas estão relacionadas com os aspectos citados acima é a sua localização no interior do CLG: a primeira encontra-se no capítulo intitulado "Objeto da Linguística", que faz parte da Introdução dessa obra; as outras duas críticas encontram-se, respectivamente, no capítulo "Natureza do signo

\footnotetext{
5 "Cette critique est restée dans l'ombre pour les éditeurs du Cours, comme elle l'est restée pour une bonne partie de la linguistique contemporaine. Qui n'en pas compris la portée et continue de s'en tenir à la conception de la nomenclature dont l'origine remonte à Aristote".
} 
linguístico" e "O valor linguístico", ambos pertencentes à parte dedicada à Linguística Sincrônica ${ }^{6}$.

A primeira crítica à nomenclatura é explicitada no CLG no capítulo em que Saussure distingue língua de linguagem e fala. Além disso, é nesse capítulo que Saussure afirma que "o ponto de vista cria o objeto". De acordo com ele,

Bem longe de dizer que o objeto precede o ponto de vista, diríamos que é o ponto de vista que cria o objeto; aliás, nada nos diz de antemão que uma dessas maneiras de considerar o fato em questão seja anterior ou superior às outras (SAUSSURE, 1973 [1916], p. 15).

Nesse sentido, a língua não é dada de antemão, é necessário que se escolha um determinado ponto de vista para analisá-la e, assim, apreender a sua natureza. Um aspecto que deve ser ressaltado é que não há um ponto de vista superior ou anterior ao outro. Talvez seja possível afirmar que estamos diante de uma escolha metodológica e, enquanto tal, essa escolha implica em um redirecionamento de toda a investigação do objeto de estudo. Essa também parece ser a opinião de Normand (2011), segundo a qual a afirmação de que "o ponto vista cria o objeto" constitui o primeiro princípio da teorização saussuriana e dominaria todos os demais ${ }^{7}$. Normand (2011) também acrescenta que

Cada ponto de vista define um domínio de observáveis, segundo uma epistemologia, neste estágio, positivista, que só é redutora caso se interprete como uma exclusão definitiva o que é somente um gesto de delimitação necessário em um determinado momento, para esclarecer as confusões e retificar o método (NORMAND, 2011, p. 19, grifo nosso).

Assim, optar por um determinado ponto de vista não implica em excluir definitivamente outros pontos de vista e, consequentemente, outros aspectos da língua. Há, portanto, a possibilidade de se distinguir "delimitação" de "exclusão": a delimitação consiste em uma escolha do que deverá ser abordado pelo linguista, enquanto que a exclusão consistiria em afirmar que determinados elementos não possuem nenhuma participação no funcionamento da língua.

\footnotetext{
${ }^{6}$ É interessante ressaltar que a primeira crítica foi realizada em uma aula do segundo curso (1908-1909), enquanto que as demais foram realizadas, respectivamente, no início e no final do terceiro curso (1910-1911). 7 No artigo "Saussure: uma epistemologia da linguística", Normand (2011) explicita quatro princípios que teriam norteado o pensamento saussuriano: i. o ponto de vista cria o objeto; ii. tudo o que está no sentimento dos sujeitos falantes é fenômeno real; iii. a língua não é uma nomenclatura, pois é forma e não substância; iv. o que é absoluto é o movimento da língua no tempo. É importante ressaltar que não nos deteremos em todos os princípios explicitados por Normand (2011), somente naqueles em que consideramos a possibilidade de relacionar com os nomes próprios.
} 
É no tópico destinado a delimitar o lugar da língua nos fatos humanos e, também, a importância da língua para a Semiologia, que Saussure explicita que até aquele momento a língua só havia sido abordada sob outros pontos de vista. Dentre esses pontos de vista, ele cita a nomenclatura: "Há, inicialmente, a concepção superficial do grande público: ele vê na língua somente uma nomenclatura, o que suprime toda a pesquisa acerca de sua verdadeira natureza" (SAUSSURE, 1973 [1916], p. 25).

Considerar a língua como uma nomenclatura implicaria, então, em não considerar o funcionamento linguístico, mas sim os aspectos exteriores a esse funcionamento, como a relação entre os nomes e os objetos. O "grande público" ao qual Saussure se refere parece ser constituído por filósofos e por outros estudiosos. Isso pode ser confirmado com a anotação de Riedlinger correspondente a essa afirmação:

\begin{abstract}
<quando se estuda a língua > como a estudam os psicólogos, <os> filósofos, ou mesmo <o grande público: de fato $>$ : $1^{0}$ eles consideram a língua como uma nomenclatura, suprimindo assim a determinação reciproca dos valores na língua por sua própria coexistência. Todas as grandezas dependem umas das outras: queremos determinar em francês o que é julgamento? Só podemos defini-lo <por> aquilo que o rodeia [...] (RIEDLINGER apud ENGLER, 1962, p. 50, tradução e grifo nossos) ${ }^{8}$.
\end{abstract}

Há vários aspectos que devem ser ressaltados nessa anotação. O primeiro deles diz respeito ao fato de que, apesar de não ser possível verificar se os filósofos aos quais Saussure se referiu nessa aula eram J.S. Mill e G. Frege, podemos afirmar que a crítica saussuriana se encaixaria perfeitamente nas teorias desses autores. E isso porque os dois filósofos partem de uma perspectiva de que os nomes têm como função se referir aos objetos. Mill (1979), por exemplo, defendia que os nomes próprios estariam associados de maneira convencional aos objetos e seriam, dessa forma, designadores rígidos, mas não teriam significado. Já Frege (1978) partia do pressuposto de que os nomes próprios teriam significado, que seria o modo de apresentação do objeto, comum a toda uma comunidade. Não obstante, é visível que neste trecho a relação entre a negação da língua como nomenclatura e o valor linguístico é evidente: a partir do momento em que se considera que a única função da língua é etiquetar objetos, tem-se que toda a complexidade do funcionamento linguístico é desconsiderada. Não haveria como afirmar que os signos são

\footnotetext{
8 " $<$ quand on étudie la langue $>$ comme l'étudient les psychologues, $<$ les $>$ philosophes, ou même $<$ comme le public : en effet $>: 1^{\circ}$ ils considèrent la langue comme une nomenclature suppriment ainsi la détermination réciproque des valeurs dans la langue par leur coexistence même. Toutes les grandeurs dépendent les unes des autres : veut-on ainsi déterminer en français ce qui est jugement? On ne peut le définir que < par> ce qui l'entoure $[\ldots]$ ".."
} 
negativos, opositivos e diferenciais, caso a língua fosse uma nomenclatura. E isso porque considerá-la dessa maneira implicaria em deter-se nos aspectos exteriores ao funcionamento linguístico.

Desse modo, é plausível afirmar que a negação da nomenclatura enquanto concepção de linguagem pode ser considerada como um dos aspectos fundamentais para a afirmação de que a língua possui uma ordem própria. E isso porque essa ordem própria baseia-se nas relações estabelecidas entre os elementos no interior do sistema linguístico e não nos aspectos exteriores a esse sistema. Nesse sentido, é interessante retomar a comparação entre o jogo de xadrez e a língua:

Mas de todas as comparações que se poderiam imaginar, a mais demonstrativa é a que se estabeleceria entre o jogo da língua e uma partida de xadrez. De um lado e de outro, estamos em presença de um sistema de valores e assistimos às suas modificações. Uma partida de xadrez é como uma realização artificial daquilo que a língua nos apresenta sob forma natural (SAUSSURE, 1973 [1916], p. 104).

Em uma partida de xadrez, o material do qual as peças são constituídas não interfere no funcionamento do jogo, conquanto que as regras permaneçam as mesmas. $\mathrm{O}$ que importa é que os jogadores joguem de acordo com as regras do jogo. Pode-se, por exemplo, utilizar uma tampinha de garrafa como uma peça e, mesmo assim, o jogo não será prejudicado. O mesmo aconteceria com a língua: o que importa são as relações estabelecidas no interior do sistema, não em seu exterior.

Podemos afirmar, portanto, que há uma relação de oposição entre a língua como nomenclatura e a língua como um sistema de valores. Nesse ponto, é importante retomarmos que a língua só pode ser considerada como um sistema de valores a partir do momento em que a natureza do signo linguístico é alterada. De acordo com Normand (2009), a concepção de signo de Saussure transforma totalmente a noção tradicional de signo, visto que ele deve ser compreendido em uma teoria semiológica que associa o social, o arbitrário e o valor (NORMAND, 2009, p. 69).

Essa afirmação de Normand (2009) leva-nos à segunda ocorrência da crítica saussuriana à nomenclatura que, como veremos, relaciona-se com a constituição do signo linguístico em significante e significado e à relação estabelecida entre essas duas faces. 


\section{A segunda crítica: a nomenclatura, o signo e o arbitrário.}

A segunda crítica presente no CLG encontra-se no capítulo destinado à natureza do signo linguístico. Nesse capítulo, Saussure nega novamente a concepção reducionista de que a língua é uma nomenclatura, para explicar de que maneira o signo linguístico constituise em sua teoria:

Para certas pessoas, a língua, reduzida ao seu princípio essencial, é uma
nomenclatura, vale dizer, uma lista de termos que correspondem a outras
tantas coisas. [...] Tal concepção é criticável em numerosos aspectos.
Supõe ideias completamente feitas, preexistentes às palavras; ela não nos
diz se a palavra é de natureza vocal ou psíquica, pois arbor pode ser
considerada sob um ou outro aspecto; por fim, ela faz supor que o
vínculo que une um nome a uma coisa constitui uma operação muito
simples, o que está muito longe da verdade (SAUSSURE, 1973 [1916], p.
79).

Como se sabe, era comum no século XIX a concepção segundo a qual o âmago da linguagem era composto pelos nomes e que a principal função da língua era dar nome aos objetos presentes no mundo. Entretanto, se a língua se restringisse a uma lista de etiquetas que nomeiam objetos, toda a sua complexidade seria perdida e não haveria a necessidade de se estudar o seu funcionamento. Além disso, um aspecto interessante a ser ressaltado nessa citação é a afirmação de que o vínculo entre um nome e uma coisa não constitui uma operação simples. Ao que nos parece, então, Saussure não nega que um nome possa se referir a objetos, mas sim que antes da relação de referência acontecer há todo um funcionamento que é interior ao sistema linguístico. A nota autógrafa correspondente a esse trecho direciona essa crítica especificamente aos filósofos:

Ao capítulo semiologia: < a maior parte das concepções que são, ou ao menos que oferecem $>$ os filósofos da linguagem fazem refletir sobre $<$ nosso primeiro pai $>$ Adão chamando para si os $<$ diversos $>$ animais e dando-lhes a cada um seu nome (SAUSSURE apud ENGLER, 1962, p. 147, tradução nossa) $)^{9}$.

É justamente após essa crítica à nomenclatura que Saussure define o signo linguístico no CLG, concebido como uma entidade composta por significante e significado, que mantêm uma relação arbitrária. Nesse ponto, é plausível afirmar que as concepções que consideram a língua como uma nomenclatura afirmam que a relação estabelecida entre os nomes e os objetos é arbitrária, enquanto Saussure defende que o arbitrário é interior ao

\footnotetext{
9 "Au chapitre sémiologie: <La plupart des conceptions que se font, ou du moin qu'offrent> les philosophes du langage font songer à < notre premier pére $>$ Adam appelant près de lui les < divers $>$ animaux et leur donnant à chacun leur nom".
} 
signo linguístico. Isso nos leva à distinção explicitada por Gadet (1990) entre arbitrário filosófico e arbitrário linguístico:

O arbitrário filosófico, com efeito, concerne na ligação entre uma coisa e seu nome. Enquanto que o arbitrário linguístico é o princípio segundo o qual um significante como [soer] não está relacionado por nenhuma ligação interior ao significado "soeur" [...] (GADET, 1990, p. 37, tradução nossa) ${ }^{10}$.

Assim, o arbitrário filosófico impõe a relação entre o nome e o referente, encontrando-se no exterior do signo. Por outro lado, o arbitrário linguístico situa-se na relação estabelecida entre significante e significado, ou seja, não há na constituição do signo linguístico um lugar para os objetos presentes no mundo. Nesse ponto, é pertinente colocar a seguinte questão: a afirmação do arbitrário filosófico negaria o arbitrário linguístico, ou vice-versa? Essa questão é de difícil resolução e podemos dizer que essa dificuldade foi percebida por Ferdinand de Saussure ao afirmar que "o princípio da arbitrariedade não é contestado por ninguém; às vezes, porém, é mais fácil descobrir uma verdade do que lhe assinalar o lugar que lhe cabe” (SAUSSURE, 1973 [1916], p. 82).

Devido à possibilidade de estabelecer o arbitrário, tanto na relação entre significante e significado quanto na relação estabelecida entre nomes e objetos, o arbitrário saussuriano é, de acordo com De Mauro (1972), cercado de mal-entendidos provenientes do fato de que a negação da nomenclatura no CLG não foi evidenciada como deveria pelos editores:

Compreendemos, portanto, como a noção de arbitrário do signo pôde ficar por tanto tempo obscurecida por um exemplo infeliz e, sobretudo, banal: a noção se fundamenta na descoberta do arbitrário de grupos de significações em significados distintos, descoberta ligada à crítica da concepção de língua como nomenclatura (DE MAURO, 1972, p. 427, tradução nossa ${ }^{11}$.

O exemplo infeliz ao qual De Mauro (1972) se refere é aquele utilizado para explicar o princípio da arbitrariedade:

\footnotetext{
10 "L'arbitraire philosophique, en effet, concerne le lien entre une chose et son nom. Alors, que l'arbitraire linguistique est le principe selon lequel un signifiant comme [soer] n'est lié par aucun rapport intérieur au signifié 'soeur' [...]".

11 "On comprend donc bien comment la notion d'arbitraire du signe dans le CLG a pu rester si longtemps obscurcie par un exemple malheureux et, surtout, banale: la notion se fonde sur la découvert de l'arbitraire des regroupements de significations en signifiées discrets, découvert liée à la critique de la conception de la langue comme nomenclature".
} 
Assim, a ideia de "mar" não está ligada por relação alguma interior à sequência de sons $\mathrm{m}-\mathrm{a}-\mathrm{r}$ que lhe serve de significante; poderia ser representada igualmente bem por outra sequência, não importa qual; como prova, temos a diferença entre as línguas e a própria existência de línguas diferentes: o significado da palavra francesa bouef ("boi") tem por significante b-ö-f de um lado da fronteira franco-germânica. E o-k-s (Ochs) do outro (SAUSSURE, 1973 [1916], p. 82, grifo nosso).

De fato, foi esse o exemplo que fundamentou um debate caloroso no século XX sobre o arbitrário na teoria saussuriana. Dentre os estudiosos que participaram desse debate, podemos citar Pichon (1937), Benveniste (2005 [1939]) e Bally (1940) ${ }^{12}$. Tanto Pichon (1937) quanto Benveniste (2005 [1939]) afirmaram que o exemplo utilizado por Saussure - sobre a diferença entre boeuf e ochs- evidenciava uma contradição na teoria saussuriana, que seria o fato de Saussure ter recorrido ao objeto exterior com o intuito de verificar o princípio da arbitrariedade. Para De Mauro (1972), esse debate pode ter sido ocasionado pelo fato de que muitos estudiosos consideraram somente as páginas em que Saussure trata do princípio da arbitrariedade ${ }^{13}$, nas quais a concepção de língua como nomenclatura encontra respaldo:

Nas páginas 100 e 101 do CLG (parece que algumas pessoas leem somente essas duas páginas) aflora a noção whitneyana de arbitrário e, com ela, a concepção da língua como nomenclatura. A ambiguidade do termo arbitrário, ainda carregada do sentido whitneyano, pode ter desempenhado um certo papel nessas duas páginas, ou seja, na lição de 2 de maio, um deslizamento, um retorno às concepções criticadas e liquidadas pelo próprio Saussure (DE MAURO, 1972, p. 443, tradução nossa) $)^{14}$.

Por arbitrário whitneyano, De Mauro (1972) entende que, na teoria de Whitney, de 1875, a relação arbitrária ocorre no exterior do signo linguístico, em sua relação com os objetos aos quais se refere. Desse ponto de vista, arbitrário não quer dizer "imotivado", mas sim "convencional" o que evidenciaria uma concepção de linguagem como nomenclatura. Ao considerarmos somente essas duas páginas, poderíamos afirmar que Saussure, de fato, recorreu ao objeto em sua definição de arbitrário e, consequentemente, haveria uma contradição em sua teoria. Mas essa afirmação teria várias implicações

\footnotetext{
12 Quanto a esse debate sobre o arbitrário linguístico, ver Engler, R. (1962). E quanto ao debate específico entre Pichon, Benveniste e Bally, conferir Henriques (2012a; 2012b).

${ }^{13} \mathrm{Na}$ edição brasileira, as páginas às quais De Mauro (1972) se refere são a 82 e a 83.

14 “Dans les pages 100 e 101 du CLG (il semblerait que certains n'aient lu que ces deux pages) affleure la notion whitneyenne de l'arbitraire et, avec elle, la conception de la langue comme nomenclature. L' ambiguité du terme arbitraire, lourd encore du sens whitneyenne, peut avoir joué un certain rôle en provoquant dans ces deux pages, c'est-a-dire, dans la leçon du 2 mai, un glissement, un retour vers des conceptions critiquées et liquidées par Saussure lui-même".
} 
prejudiciais à teoria saussuriana. Dentre elas, poderíamos afirmar que não seria possível conceber o valor linguístico, tal como é explicitado por Saussure na seguinte passagem:

Não só os dois domínios ligados pelo fato linguístico são confusos e amorfos como a escolha que se decide por tal porção acústica para tal ideia é perfeitamente arbitrária. Se esse não fosse o caso, a noção de valor perderia algo de seu caráter, pois conteria um elemento imposto de fora (SAUSSURE, 1973 [1916], p. 132).

Dessa forma, a teoria do valor não seria possível se os elementos da língua trouxessem em si mesmos uma positividade ou se as ideias fossem dadas de antemão. Considerando esses aspectos, somos levados a afirmar que a relação arbitrária entre significante/significado possui um papel fundamental na teoria saussuriana e as duas páginas nas quais as formulações saussurianas sobre o arbitrário evidenciam a concepção da língua como nomenclatura devem ser investigadas no conjunto da teoria saussuriana. Assim, concordamos com De Mauro (1972), segundo o qual

O sentido profundo do princípio da arbitrariedade, sob a indicação explícita do próprio Saussure, deve ser compreendido não somente pela formulação dessas duas páginas, mas considerando todo o CLG: deve-se considerar antes de tudo a doutrina da língua relacional segundo a qual as diferenças da língua são "independentes" das características intrínsecas da substância semântica e da substância acústica [...] (DE MAURO, 1972, p. 443, tradução nossa) ${ }^{15}$.

O arbitrário saussuriano deve ser tratado, desse modo, enquanto pertencente a uma concepção que considera a língua como forma e não substância, ou seja, uma concepção que defenda que a língua é construída de entidades psíquicas que se relacionam e por meio dessas relações adquirem valor, sem a interferência de nenhum tipo de substância - objetos ou sons. Deparamo-nos, então, com uma das afirmações mais categóricas e ao mesmo tempo mais fortes da teoria saussuriana. Afirmar que a língua é forma e não substância é a conclusão de todo o deslocamento teórico efetuado por Saussure: ela é uma forma porque o arbitrário não está na relação entre signo e objeto, mas sim entre significante e significado. Além disso, é justamente por serem arbitrários que os signos linguísticos adquirem valor por intermédio das relações que estabelecem no interior do sistema. Tanto a arbitrariedade quanto o valor linguístico, aspectos fundamentais da teoria saussuriana,

15 "Le sens profond du principe de l'arbitraire, sur l'indication explicite de Saussure lui-même, doit être compris non pas en regardant seulement la formulation de ces deux pages, mais en regardant tout le CLG: on doit considérer avant tout la doctrine de la langue connexe selon laquelle les distinctions de la langue sont 'indépendantes' des caractéristiques intrinsèques de la substance sémantique et de la substance acoustique $[\ldots] "$. 
consolidam a negação da língua como nomenclatura. Nesse ponto, é pertinente que nos detenhamos na terceira crítica à nomenclatura, que coloca em jogo a distinção entre significação e valor.

\section{A terceira crítica: significação, valor linguístico e parole}

A terceira menção à nomenclatura está localizada justamente no capítulo destinado ao valor linguístico e relaciona-se com a distinção entre significação e valor:

O valor tomado em seu aspecto conceitual, constitui, sem dúvida, um elemento da significação, e é dificílimo saber como esta se distingue dele, apesar de estar sob sua dependência. É necessário, contudo, esclarecer essa questão, sob pena de reduzir a lingua a uma simples nomenclatura (SAUSSURE, 1973 [1916], p. 133, grifo nosso).

A diferença entre valor e significação é algo dificultoso de se estabelecer na teoria saussuriana. De acordo com Coelho (2013, p. 1), “a relação entre esses dois termos não é estabelecida de forma clara, não sendo possível delimitar se o valor é um elemento da significação, ou o contrário". Se tomarmos essa distinção da maneira com que ela é exposta neste capítulo do CLG, temos que: o valor advém da relação estabelecida entre os termos no sistema, enquanto que a significação é a contraparte da imagem auditiva ou a relação entre significante e significado ${ }^{16}$.

A questão que deve ser colocada aqui é qual seria o motivo de Saussure afirmar a necessidade de se esclarecer essa distinção, sob pena de reduzir a língua a uma simples nomenclatura? Uma das respostas a essa pergunta pode ser o fato de que, nas concepções que consideram a língua como uma simples etiqueta, o lado conceitual do signo é, muitas vezes, considerado como o próprio objeto. Assim, não há a relação entre significante e significado, mas sim entre significante e objeto, o que exclui qualquer possibilidade de haver significação e valor linguístico.

Por outro lado, alguns estudiosos afirmam que a diferença entre significação e valor consistiria no fato de que a primeira se encontra no âmbito da fala enquanto a segunda se encontra no âmbito da língua. Dentre esses autores, podemos citar Bally (1940) e Burger (1961). Bally (1940), no artigo "L’arbitraire Du signe: valeur et signification”, no qual

\footnotetext{
${ }^{16}$ Há várias discussões em torno da distinção entre valor e significação. Dentre os autores que tratam dessa problemática, podemos citar Coelho (2013) e Marques (2013).
} 
discute sobre o arbitrário saussuriano e também sobre as afirmações de Pichon (1937) e Benveniste (2005 [1939]), afirma que

Se o arbitrário do signo não parece ser afetado pela crítica exposta acima, ela nos oferece a possibilidade de colocar em evidência dois aspectos fundamentais do signo linguístico, sobre a distinção entre representação sensorial atual e conceito virtual. O reflexo linguistico da primeira será chamado aqui de significação; assim arbre tem uma significação, quando en falo da árvore que faz sombra em minha casa, quanto ao conceito virtual ligado à palavra na memória, sem nenhum contato com a realidade, chamaremos de valor subjetivo ou simplesmente valor (BALLY, 1940, p. 194, tradução e grifo nossos) ${ }^{17}$.

Para Bally (1940) há, portanto, uma distinção fundamental entre valor e significação. O valor linguístico, ou seja, as relações estabelecidas entre os termos no interior do sistema não teriam, de fato, nenhuma relação com os objetos exteriores. Essa relação seria estabelecida no âmbito da parole, a partir do momento em que um falante fala de algo para alguém. Na continuação desse artigo, Bally (1940) afirma que

É somente na fala, no discurso, que o signo, por um contato com a realidade tem uma significação (p. ex. 'A árvore que você vê lá em baixo não possui frutas'), e é somente na língua, no estado latente, que esse mesmo signo desencadeia um feixe de associações memoriais que constituem seu valor (p. ex. árvore: arbusto, árvore: tronco, árvore: abeto, faia; árvore: floresta, etc.) (BALLY, 1940, p. 194-195, tradução nossa ${ }^{18}$.

A posição de Bally (1940) parece evidenciar a interdependência entre língua/fala e a possibilidade de se pensar a relação de referência como algo pertencente ao domínio da fala. Nesse ponto, é interessante ressaltar que todos os signos linguísticos estariam submetidos tanto ao valor quanto à significação e não somente os nomes próprios. $\mathrm{Na}$ verdade, veremos no próximo tópico que os nomes próprios são considerados por Saussure como palavras isoladas, o que poderia ser entendido como uma ausência de valor, mas não de significação.

Além de Bally (1940), Burger (1961) também defendeu que a distinção entre valor e significação envolve a distinção entre língua e fala. De acordo com ele,

\footnotetext{
17 'Si l'arbitraire du signe ne semble pas atteint par la critique exposée plus haut, celle ci nous offre l'occasion de mettre en relief deux aspects fondamentaux du signe linguistique, sur la base de la distinction entre représentation sensorielle actuelle et concept virtuel. Le reflet linguistique de la première sera appelé ici signification objective, ou simplement signification; ainsi arbre a une signification, lorsque je parle de l'arbre qui ombrage ma maison; quant au concept virtuel attaché au mot dans la mémoire, sans aucun contact avec la réalité, nous l'appellerons valeur subjective, ou simplement valeur".

18 "C'est seulement dans la parole, dans le discours, que le signe, par contact avec la réalité, a une signification (p. ex. "L'arbre que vous voyez là-bas ne porte pas de fruits"), et c'est seulement dans la langue, à l'état latent, que ce même signe déclenche un faisceau d'associations mémorielles qui constituent sa valeur (p. ex.arbre: arbuste, arbre: tronc, arbre: sapin, hêtre; arbre: forêt, etc.)".
} 
se a língua é um sistema de valores, se é do valor que o sentido depende, isso significa que é o valor, entidade puramente virtual, que permite a manifestação, no discurso, de significações diversas as quais dependem das relações entretidas com os outros valores do sistema (BURGER, 1961, p. 7 , tradução nossa) ${ }^{19}$.

Assim, para Burger (1961) a significação depende do valor, ou seja, uma determinada palavra pode adquirir várias significações conquanto que essas significações sejam possibilidades oferecidas pelas relações dos termos no interior do sistema. Nesse sentido, quando Saussure afirma que é necessário distinguir valor de significação, sob pena de reduzir a língua a uma nomenclatura, somos levados a considerar que a língua só não é uma nomenclatura, porque ela não se restringe às significações que uma palavra pode adquirir.

Após a análise das passagens em que Saussure critica as concepções que consideram a língua como uma nomenclatura, podemos depreender o seguinte: as críticas à nomenclatura encontram-se presentes em momentos decisivos da teoria saussuriana. Esses momentos são, respectivamente: a definição do objeto língua, o arbitrário linguístico e a distinção entre valor e significação. A importância dessas críticas na teoria saussuriana parece-nos, portanto, evidente e, desse modo, concordamos com Normand (2011), segundo quem um dos princípios epistemológicos que nortearam as considerações de Saussure sobre a língua seria justamente a negação de que ela é uma nomenclatura e a afirmação de que ela é uma forma e não uma substância (NORMAND, 2011, p. 24). Aqui, a relação entre as críticas à nomenclatura, o arbitrário e a teoria do valor torna-se evidente, tendo em vista que só é possível negar a língua como nomenclatura, ao efetuar o deslocamento do princípio da arbitrariedade para o interior do signo, postulando que ele é negativo, opositivo e diferencial ${ }^{20}$.

Levando em consideração o que foi explicitado, poderíamos então afirmar que Saussure nega a nomenclatura? Antes de respondermos a essa questão devemos definir o que entendemos por "negação". No ramo da Lógica, a negação de uma proposição é a sua contradição (BLACKBURN, 1997, p. 263). Há, nas considerações saussurianas, a negação das concepções que consideram a língua enquanto uma simples nomenclatura, mas essa

\footnotetext{
19 "Si la langue est un système de valeurs, si c'est de la valeur que dépend le sens, cela signifie que c'est la valeur, entité purement virtuelle, qui permet la manifestation, dans le discours, de significations diverses mais qui toutes dépendent des rapports qu'elle entretient avec les autres valeurs du système".

20 Nesse ponto, é plausível retomar a distinção efetuada por Gadet (1990), segundo a qual o arbitrário filosófico consistiria na relação entre o nome e o referente, encontrando-se no exterior do signo linguístico, enquanto que o arbitrário linguístico estaria situado na relação estabelecida entre significante e significado, ou seja, no interior do signo linguístico.
} 
negação incide somente sobre a generalização da nomenclatura como modo de funcionamento da língua, ou seja, na restrição de que a única função da língua é nomear objetos do mundo. Isso não quer dizer que o ato de nomear não pertença, de algum modo, ao funcionamento da língua. Nesse sentido, concordarmos com a afirmação de Chiesa (2008):

rejeitar a concepção de linguagem enquanto nomenclatura não implica em rejeitar a nomenclatura enquanto caso particular da linguagem e, por consequência de uma série de palavras, a saber os nomes que comportam uma referência aos objetos dos quais os locutores são conscientes. Tratase, então, de reexaminar a questão da nomenclatura nos escritos de Saussure (CHIESA, 2008, p. 11, tradução nossa) ${ }^{21}$.

Assim, é plausível afirmar que o que Saussure nega é a redução da língua a uma nomenclatura, como se a sua única função fosse etiquetar objetos presentes no mundo. Não obstante, Saussure não nega a nomenclatura enquanto caso particular da linguagem, apesar de deixar transparecer que os nomes próprios possuem especificidades que lhes diferenciam dos demais signos. Dessa forma, é interessante que nos detenhamos na única vez em que o nome próprio é mencionado no CLG, no capítulo destinado ao fenômeno analógico.

\section{$O$ isolamento do nome próprio}

Nos tópicos anteriores, explicitamos as críticas saussurianas às concepções que postulam a língua como uma nomenclatura. Com a análise dessas críticas, percebemos que elas se relacionam com aspectos importantes da teoria saussuriana. Ademais, tentamos evidenciar que Saussure nega a nomenclatura enquanto generalização do funcionamento linguístico e não enquanto caso particular da linguagem. Neste tópico, pretendemos abordar a única vez que o nome próprio é mencionado nas formulações saussurianas presentes no CLG. Essa ocorrência encontra-se na parte dedicada à Linguística Diacrônica, sendo que nos deteremos no capítulo IV e no capítulo V, nos quais Saussure (1973 [1916]) faz considerações sobre a analogia e sobre a evolução da língua.

\footnotetext{
21 "Le rejet de la conception du langage comme une nomenclature n'implique pas le rejet de la nomenclature en tant que cas particulier du langage et par conséquent d'une série de mots, à savoir les noms, qui comportent une référence à des objets dont les locuteurs sont conscients. Il s'agit des lors de réexaminer la question de la nomenclature dans les écrits de Saussure”.
} 
A analogia pode ser definida de maneira opositiva ao fenômeno fonético. De acordo com Saussure (1973), o efeito do fenômeno fonético é contrabalanceado pela analogia, tendo em vista que ela se constitui enquanto um fenômeno que acarreta transformações normais do aspecto exterior das palavras. Além disso, o fenômeno analógico, "supõe um modelo e sua imitação regular. Uma forma analógica é uma forma feita à imagem de outra ou de outras, segundo uma regra determinada" (SAUSSURE, 1973 [1916], p. 187).

De acordo com De Mauro (1972), a analogia desempenha um papel fundamental na formação dos sintagmas,

Papel essencial se se considera o fato de que, para Saussure, os sintagmas são não somente as 'palavras', mas também as frases, de modo que a analogia é a fonte de criatividade da língua, a via através da qual a língua gera um conjunto teoricamente infinito de frases (DE MAURO, 1972, p. 472, tradução nossa $)^{22}$.

Interessa-nos ressaltar que a analogia é um fenômeno regular e não uma irregularidade. Juntamente com as mudanças fonéticas, é ela que proporciona a evolução das línguas, ou seja, "o processo pelo qual estas passam de um estado de organização para outro" (SAUSSURE, 1973 [1916], p. 189).

No que diz respeito à natureza do fenômeno analógico, Saussure explicita que a analogia não é uma mudança, tal como o fenômeno fonético, e sim uma criação da língua. Se, na mudança fonética, uma forma nova só surge quando a forma antiga for anulada, na analogia, por sua vez, há a criação de uma nova palavra a partir de outra já existente na língua, sendo que essas duas palavras conviverão. Para ilustrar o fenômeno analógico, Saussure (1973) utiliza-se da quarta proporcional ${ }^{23}$. Assim,

$$
\begin{aligned}
& \text { réaction : réactionnaire }=\text { répression }: \mathrm{x} \\
& \qquad \mathrm{x}=\text { répressionaire }
\end{aligned}
$$

A fórmula acima nos diz que já existiam na língua as formas "réaction", "réactionnaire" e "répression". Pelo fenômeno de analogia criou-se - utilizando como

22 "Rôle essentiel si l'on tient compt du fait que pour Saussure les syntagmes sont non seulement les 'mots', mais aussi les phrases, si bien qui l'analogie est source de la créativité de la langue, la voie à travers laquelle la langue génère l'ensemble théoriquement infini des phrases".

23 De acordo com Saussure, há dois métodos para se ilustrar a analogia: pela quarta proporcional, fórmula matemática, e pela análise e reconstrução dos elementos fornecidos pela língua. Saussure opta pela quarta proporcional na medida em que as gramáticas europeias utilizam esse método (SAUSSURE, 1973 [1916], p. 194). 
modelo o par "réaction : réactionnaire”, o par "répression : répressionaire”. É perceptível que não há a substituição da forma antiga pela nova forma analógica. E isso porque a analogia, diferentemente da mudança fonética, não objetiva substituir uma forma antiga por uma nova.

Saussure (1973) explicita que a analogia possui um caráter estritamente psicológico e gramatical. Gramatical, porque é necessário que haja a consciência e a compreensão de uma relação que une as formas entre si, e psicológico porque a ideia faz-se necessária no processo de criação analógica. Isso quer dizer que só há a necessidade de se usar uma forma antiga para criar uma nova a partir do momento em que essas duas formas se combinam no espírito. A analogia se resume, então, em "um aspecto do fenômeno de interpretação, uma manifestação da atividade geral que distingue as unidades para utilizá-las em seguida. Eis porque dizemos que é inteiramente gramatical e sincrônica" (SAUSSURE, 1973 [1916], p. 193).

$\mathrm{O}$ nome próprio aparece no capítulo $\mathrm{V}$, no qual são tratados os aspectos relacionados à analogia e à evolução. Saussure (1973) inicia esse capítulo afirmando que "Nada entra na língua sem ter sido antes experimentado na fala, e todos os fenômenos evolutivos têm sua raiz na esfera do indivíduo" (SAUSSURE, 1973 [1916], p. 196). Aqui percebemos a importância de se distinguir língua e fala e de considerá-las enquanto duas esferas interdependentes ${ }^{24}$. As criações analógicas têm, portanto, sua origem na fala, mas nem todas serão adotadas pela língua:

\footnotetext{
A língua retém somente uma parte mínima das criações da fala, mas as que duram são bastante numerosas para que se possa ver, de uma época a outra, a soma das formas novas dar ao vocabulário e à gramática uma fisionomia inteiramente diversa (SAUSSURE, 1973 [1916], p. 196).
}

Percebe-se assim que o fenômeno analógico e o fenômeno fonético proporcionam a transformação da língua ao longo do tempo. Aqui, notamos explicitamente a questão da mutabilidade e da imutabilidade do signo à medida que, ao mesmo tempo, a língua se conserva e é transmitida por gerações, enquanto ela se modifica no âmbito da fala dos indivíduos e por influência do tempo.

\footnotetext{
24 Apesar de Saussure ressaltar em várias passagens do CLG que o fenômeno analógico possui sua origem no âmbito da fala, é conveniente ressaltarmos que isso não implica que a analogia seja restrita a esse domínio. Acreditamos que é justamente por intermédio do fenômeno analógico que a interdependência entre língua e fala pode ser comprovada.
} 
Poderíamos pensar, portanto, que todos os sintagmas de uma língua, tanto palavras como frases, submetem-se ao fenômeno da analogia. Todavia, esse pensamento é errôneo porque, de acordo com Saussure, as únicas palavras que não se submetem à analogia são os nomes próprios e geográficos:

As únicas formas sobre as quais a analogia não tem poder nenhum são naturalmente as palavras isoladas, tais como os nomes próprios, especialmente os nomes de lugares (cf. Paris, Genève, Agen etc.), que não permitem nenhuma análise $\mathrm{e}$, por conseguinte nenhuma interpretação de seus elementos; nenhuma criação concorrente surgiu a par deles (SAUSSURE, 1973, p. 201).

A afirmação de que os nomes próprios escapam ao fenômeno analógico leva-nos a pensar que o processo de formação dessa categoria linguística não ocorre por analogia. Ao que nos parece, isso parece ser pertinente a partir do momento em que consideramos que a analogia é um processo de criação que utiliza de formas já existentes na língua e que funciona a partir dos mecanismos associativos e sintagmáticos. Se o mecanismo associativo é necessário para que haja criação analógica, logo é necessário que uma ou mais séries associativas sejam acessadas nesse processo, o que não parece ocorrer com os nomes próprios: ao criar um nome próprio como "Leydianne", por exemplo, não parece haver uma ideia inerente ao morfema "leydi" e outra ao morfema "anne". Assim, somos levados a considerar que existe um processo de criação do nome próprio, mas ele não ocorre pela analogia.

Dessa forma, de que maneira aconteceria esse processo? Se levarmos em consideração o conteúdo do CLG, podemos afirmar que é pouco provável que um nome próprio seja formado por aglutinação. E isso porque, de acordo com Saussure, a aglutinação consiste em

que dois ou mais fenômenos originariamente distintos, mas que se encontram frequentemente em um sintagma no seio da frase, se soldem em uma unidade absoluta dificilmente analisável.. Tal é o processo aglutinativo: processo, dizemos, e não procedimento, pois essa última palavra implica uma vontade, uma intenção, e a ausência de vontade é justamente um caráter essencial da aglutinação (SAUSSURE, 1973, p. 205).

Assim, se o processo de aglutinação necessita que duas formas sejam encontradas constantemente em um sintagma para que se unam, um nome próprio não se encaixaria nesse processo devido ao fato de que não parece haver relação com as posições ocupadas pelas formas em um sintagma. Além disso, o processo aglutinativo ocorre de maneira 
inconsciente, ou seja, não há nem intenção nem vontade na constituição de uma forma por aglutinação. Assim, à primeira vista o nome "Mariana" poderia ser considerado como o resultado de um processo aglutinativo. Entretanto, temos dois motivos para negar a aglutinação nesse caso: o primeiro deles diz respeito ao fato de que os morfemas Mari - e ana não se encontram frequentemente em um sintagma, ou seja, em uma frase. O segundo motivo diz respeito ao fato de que a aglutinação é um processo inconsciente. Ora, ao batizar uma criança com o nome de Gleidsmari, por exemplo, eu estou consciente de que esse nome é a junção de dois nomes já existentes: Gleidson e Maria.

Nesse sentido, o nome próprio parece não se encaixar em nenhum desses dois processos de formação de palavras. Ao que nos parece, então, Saussure teria percebido a produtividade morfológica limitada do nome próprio. Talvez não exista um número considerável de formas que sejam derivadas de nomes próprios em todas as línguas, mas é inegável que há a possibilidade de se formar novos nomes a partir de nomes próprios já existentes.

\section{Considerações finais}

O nome próprio é uma categoria linguística que oferece obstáculos em sua delimitação não só no âmbito da Linguística, como também da Filosofia da Linguagem. Considerando a importância de Ferdinand de Saussure para a Linguística Moderna, nos propusemos, neste artigo, a abordar o tratamento dado a essa categoria linguística no Curso de Linguística Geral.

Apesar de haver estudiosos como Gary-Prier (1991) e Seiler (2006), que defenderam a ausência de elaborações sobre essa categoria linguística na teoria saussuriana, acreditamos ter evidenciado que, na verdade, ela pode ser percebida de duas maneiras: de uma maneira negativa e uma maneira positiva. Não obstante, os nomes próprios se relacionam com o arbitrário, o valor e a fala, que são aspectos importantes no constructo teórico saussuriano.

De qualquer forma, essa produtividade limitada ou "isolamento", nas palavras de Saussure, leva-nos a considerar a possibilidade de entrever uma diferença entre nomes próprios e nomes comuns. Podemos, então, colocar a seguinte questão: por qual motivo os 
nomes próprios se diferenciariam dos demais signos ao ponto de oferecerem resistência à analogia e à aglutinação? Seria o nome próprio um caso particular da linguagem? Ao que nos parece, os nomes próprios possuiriam alguma diferença dos outros signos linguísticos, pois não parecem estabelecer, do ponto de vista saussuriano, relações com os outros signos da língua. Ora, quais são as implicações de afirmar que os nomes próprios são palavras isoladas em uma teoria que considera a língua como um sistema fundamentado nas relações de seus termos?

Responder essas questões é uma tarefa árdua e, infelizmente, não cabe nestas páginas. Entretanto, esses questionamentos nos servem para evidenciar dois pontos importantes: o primeiro concerne à natureza ímpar da categoria linguística dos nomes e o segundo à produtividade das elaborações saussurianas presentes no CLG que, mesmo sendo uma obra centenária, ainda permanece atual e suscita indagações.

\section{Referências}

BALLY, C. L'arbitraire du signe: valeur et signification. Le Français Moderne, ano 8, $n^{\circ}$ 3, p. 193-206, jun./jul. 1940.

BLACKBURN, S. Mill, Jonh Stuart. In: Dicionário Oxford de filosofia. Rio de Janeiro: Jorge Zahar, 1997, p. 250-251.

BENVENISTE, E. A natureza do signo linguístico. In: Problemas de linguística geral I. Campinas: Pontes Editores, 2005 [1939].

BURGER, A. Signification et valeur du suffixe verbal français -ç-. Cahiers Ferdinand de Saussure. Revue suisse de linguistique générale, n 18. Genebra: Librairie Droz, 1961, p. 5 21.

CHIESA, C. Saussure, Aristotel et l'onymique. Cahiers Ferdinand de Saussure. Revue suisse de linguistique générale, $\mathrm{n}^{\circ}$ 61. Genebra: Librairie Droz, 2008, p. 5-21.

COELHO, M. P. Significação em Saussure: os três cursos de linguística geral. In: Anais do Simpósio Internacional de Letras e Linguística, v. 3 nº 1. Uberlândia: EDUFU, 2013.

COELHO, M. P.; HENRIQUES, S. M. A fala em Ferdinand de Saussure: um conceito relacional, opositivo e negativo. Revista Domínios da Linguagem, Uberlândia, v. 8, no 1 , p. 645-653, jan./jun. 2014.

DE MAURO, T. Introduction. In: SAUSSURE, F. de. Cours de linguistique générale: édition critique par Tullio de Mauro. Paris: Payot, 1972. 
ENGLER, R. Théorie et critique d'un príncipe saussurien: l'arbitraire du signe. Cahiers Ferdinand de Saussure, n 19. Genebra: Librairie Droz, 1962, p. 5-66.

FREGE, G. Sobre o sentido e a referência. In: Lógica e filosofia da linguagem. São Paulo: Cultrix, 1978, p. 59-86.

GADET, F. Saussure: une science de la langue. Paris: Press universitaire, 1990.

GARY-PRIEUR, M-N. Le nom propre constitue-t-il une catégorie linguistique?. Langue Française, v. 92, p. 4-25, 1991.

HENRIQUES, S. M. O princípio da arbitrariedade e a referência em Ferdinand de Saussure. Revista e-scrita, Nilópolis, v. 3, nº 1 B, p. 189-202, 2012a.

Le nom propre dans les manuscrits saussuriens. Congrès Mondial de

Linguistique Française, 3, v. 1, p. 757-771, 2012b.

O nome próprio nas elaborações de Ferdinand de Saussure. Dissertação (Mestrado em Estudos Linguísticos). Uberlândia: Universidade Federal de Uberlândia, 2014.

MARQUES, A. C. M. Significação: a elaboração de uma noção saussuriana no CLG. In: Anais do Simpósio Internacional de Letras e Linguística, v. $3, \mathrm{n}^{\circ} 1$. Uberlândia: EDUFU, 2013.

MILL, J. S. Sistema de lógica dedutiva e indutiva: exposição dos princípios da prova e dos métodos de investigação científica. São Paulo: Abril Cultural, 1979, p. 82-257.

NORMAND, C. Saussure. Trad. Ana de Alencar e Marcelo Diniz. São Paulo: Estação Liberdade, 2009.

Saussure: uma epistemologia da linguística. In: SILVEIRA, Eliane M. (Org.). As bordas da linguagem. Uberlândia: EDUFU, 2011, p. 11-30.

PICHON, E. La linguistique en France: problèmes et méthodes. Journal de Psychologie Normale et Pathologique, Paris, v. 34, p. 25-48, 1937.

SAUSSURE, F. de. Curso de Linguística Geral. 5 ed. Editado por Charles Bally \& Albert Sechehaye com a colaboração de Albert Riedlinger. Trad. A. Chelini, J. P. Paes e I. Blikstein. São Paulo: Cultrix, 1973 [1916].

SEILER, H. Signifiant, siginifié et la communication. In: SAUSSURE, Louis de. Nouveaux regards sur Saussure: mélanges offerts à René Amacker. Génève: Librairie Droz, 2006. 


\begin{abstract}
In this work we aim to investigate Ferdinand de Saussure's considerations about the linguistic cathegory of proper names, specifically in the work responsible by the foundation of Modern Linguistics: Course in General Linguistics. In order to comprehend in which way the proper name is considered in that work, we prioritize two main points: the denial of nomenclature and the single mention of this category made in the CGL. We start from the assumption that, although it is not evident, both the denial of nomenclature and the proper names are related with important aspects of Saussure's theory, such as the arbitrariness of sign, the value and the speech.
\end{abstract}

Keywords: Proper names. Ferdinand de Saussure. CLG. Arbitrariness

Recebido em: 06/05/2018.

Aceito em: 05/07/2018. 